\section{Catalytic Oxidation of Ethanol on Gold Electrode in Alkaline Media}

\author{
R B de Lima, H Varela*
}

Instituto de Química de São Carlos, Universidade de São Paulo, C.P. 780, CEP 13560-970, São Carlos, SP, Brazil

* Corresponding author: varela@iqsc.usp.br

\begin{abstract}
This work presents a study of the catalytic oxidation of ethanol on polycrystalline gold electrode in alkaline media. The investigation was carried out by means of chronoamperometry, cyclic voltammetry, and in situ FTIR spectroscopy. The main goal was to investigate the early stages of ethanol electrooxidation, namely at fairly low potentials ( $E=600 \mathrm{mV}$ vs. RHE) and for moderate reaction times ( $t<300 \mathrm{~s})$. Chronoamperometric experiments show a current increase accompanying the increasing in the ethanol concentration up to about $2 \mathrm{M}$ and then a slight decrease at $3 \mathrm{M}$. Adsorbed $\mathrm{CO}$ has been observed as early as about $200 \mathrm{mV}$ vs. RHE and indicates that the cleavage of the $\mathrm{C}-\mathrm{C}$ bond might occur, probably to a small extent, at very low overpotentials during ethanol adsorption on gold surface. The amount of dissolved acetate ions produced during the chronoamperomentry was followed by the asymmetric stretching band at $1558 \mathrm{~cm}^{-1}$ as a function of time, and found to increase linearly with time up to $300 \mathrm{~s}$. This allowed estimating the reaction order of acetate formation with respect to ethanol concentration.
\end{abstract}

\section{Introduction}

Mainly thanks to its potential use in low temperature fuel cells, ethanol electrooxidation has been a matter of abiding interest to electrochemists from both fundamental and applied points of view [1-16]. Platinum and platinum-based electrodes are the main catalysts in acid media and different oxidation products such as acetaldehyde $\left(\mathrm{CH}_{3} \mathrm{CHO}\right)$, acetic acid $\left(\mathrm{CH}_{3} \mathrm{COOH}\right)$ and, to a lesser extent, carbon dioxide $\left(\mathrm{CO}_{2}\right)$ have been identified. A severe limitation however, is the production of strongly adsorbed intermediates resulting of the $\mathrm{C}-\mathrm{C}$ cleavage, namely $\mathrm{CO}$ and other $\mathrm{H}$-containing residues which cause a significant loss of efficiency. Alternative materials include binary and ternary catalysts where $\mathrm{Ru}[12$, 17, 18,], Os[19], Sn[12, 7 18,20,21], In[20], Re[7], Pd[18], $\mathrm{W}[18], \mathrm{Mo}[22]$, etc. are used together with platinum. By far less studied are the electrocatalytic properties of gold surfaces towards C1 and C2 molecules [23-25].

In electrochemical environment, gold can display remarkable activity, principally in alkaline media, where it is considered a superior catalyst for CO electrooxidation [2629], and particularly active towards the electrooxidation of $\mathrm{C} 2$ saturated organic compounds containing $-\mathrm{CHO}$ and $-\mathrm{CH}_{2} \mathrm{OH}$ groups [30]. Weaver and collaborators [31] used electrochemical experiments coupled to in situ FTIR spectroscopy and compared the electrooxidation of ethylene glycol on gold, platinum and nickel electrodes. One of the main findings was that gold electrode was capable of producing carbonate in a series of steps involving long-lived solution intermediates, whereas on platinum, the conversion of ethylene glycol into carbonate occurs inherently via adsorbed intermediates [31]. Catalytic oxidation of ethanol on gold electrode has been studied by Tremiliosi-Filho et al. [32]. Gold nanoparticles have been used as catalysts towards formaldehyde [33] and methanol [34] electrooxidation in alkali. Nevertheless, the amount of spectroscopic information on the electrooxidation of $\mathrm{C} 1$ and $\mathrm{C} 2$ molecules on gold electrode in alkaline media is rather small when compared with platinum in acidic media. It is noteworthy the growing interest in fuel cell relevant reactions in alkali mainly due to the recent advance in alkaline polymer membranes [35-37] and also to the possible application in membrane-free laminar flow fuel cells [38-40].

Inthepresentcontribution, weinvestigatetheelectrocatalysis of ethanol oxidation on polycrystalline gold electrode in alkaline media. The experiments were carried out by means of chronoamperometry, cyclic voltammetry, and in situ FTIR spectroscopy. The studies were focused on the early stages of ethanol electrooxidation, namely at low potentials ( $E=600 \mathrm{mV}$ vs. RHE) and for relatively short times ( $\mathrm{t}<300 \mathrm{~s})$.

\section{Experimental}

The working electrode was either a polycrystalline disk shaped gold electrode $\left(1.0 \mathrm{~cm}\right.$ in diameter and real area of $1.2 \mathrm{~cm}^{2}$, 
see below) polished to a mirror finish or a flag like gold electrode (real area of $2.3 \mathrm{~cm}^{2}$ ). The real surface area was calculated by utilizing the charge density involved in the formation of a monolayer de AuO [41]. For cyclic voltammetry and chronoamperometry experiments the counter electrode was a gold sheet. In the IR experiments a gold sheet bent in a flat ring shape of $4.7 \mathrm{~cm}^{2}$ in geometric area was used as counter electrode. The reference electrode was a reversible hydrogen electrode, and all potentials are quoted with respect to it (RHE). Solutions were prepared with ethanol 99.9 \% (J. T. Baker) and $\mathrm{KOH} 99.99 \%$ (Aldrich). In all experiments, the electrode was polarized at $50 \mathrm{mV}$ vs. RHE and nitrogen (White Martins $99.99 \%$ ) was bubbled for some minutes in order to homogenize the solution. During the measurements the $\mathrm{N}_{2}$ flow was maintained over the solution to assure that the cell atmosphere was free of oxygen. Either purified water (Milli - Q system) or deuterium oxide was used as solvent. All experiments were performed at $25^{\circ} \mathrm{C}$.

Cyclic voltammetry and chronoamperommetry experiments were performed with a Solartron potentiostat model SI 1287. IR spectra were measured using a spectrometer Nicolet, model Nexus 670, equipped with a MCT detector.

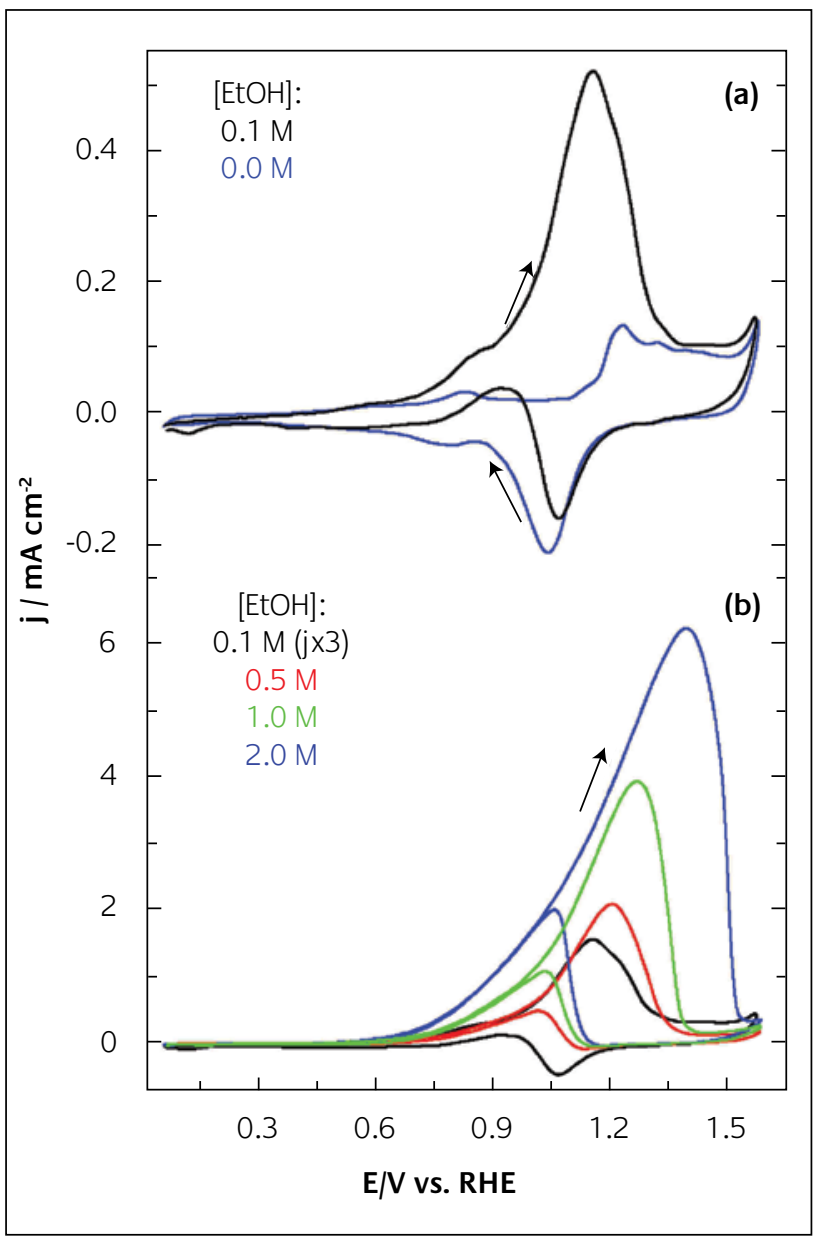

Figure 1

(a) Cyclic voltammogram for a polycrystalline Au electrode in aqueous $0.1 \mathrm{M} \mathrm{KOH}$ solution (solid line) and after addition of $0.1 \mathrm{M} \mathrm{CH}_{3} \mathrm{CH}_{2} \mathrm{OH}$ (dotted line). (b) Same as (a) but with different ethanol concentrations. Current densities referred to active surface (see text for details). Sweep rate: $100 \mathrm{mVs}^{-1}$
The spectro-electrochemical cell [42] was fitted with a $60^{\circ}$ $\mathrm{CaF}_{2}$ prismatic window. The spectra were calculated as the normalized difference of two spectra obtained at a potential of interest, $R$, and at a reference potential $R_{0}$. As previously presented [43], this procedure results in spectra with negative and positive bands for species that are present at the working and at the reference potential, respectively.

\section{Results and discussion}

Figure 1(a) shows the cyclic voltammogram of a polycrystalline gold in base electrolyte (0.1 M of $\mathrm{KOH}$, blue curve) and after addition of $0.1 \mathrm{M}$ of ethanol (black curve). The voltammetric profile for gold in alkaline media is in agreement with previously published data [44] and attests the quality of the gold electrode as well as the cleanness of the system. The voltammetric response in the presence of ethanol shows that the electrooxidation starts at about $600 \mathrm{mV}$ vs. RHE during the positive-going sweep. Although not apparent in the cyclic voltammogram in the absence of ethanol, at this potential the gold surface is already sparsely populated by oxygenated species [23]. As already documented and further discussed below, the presence of pre-adsorbed oxygenated species is crucial for the ethanol electrooxidation. As the sweep proceeds, an oxidation wave is discernible at about $1150 \mathrm{mV}$ vs. RHE which nearly coincides with the formation of fully developed gold oxide layer. Afterwards, a current plateau at the same current levels than that of the sweep in base medium is observed and evidences that ethanol oxidation is nearly negligible at those potentials and on an oxide covered gold surface. During the negative-going sweep, a small oxidation peak is observed at ca. $900 \mathrm{mV}$ vs. RHE. This reactivation can be attributed to the reduction of gold oxide $[41,45]$, which is similar to the behaviour observed in platinum and platinum based catalysts. Overall, the results presented for ethanol electrooxidation on gold surface in alkaline medium are rather similar to that previously reported by Tremiliosi-Filho et al. [32].

The effect of ethanol concentration has been studied and typical cyclic voltammograms for four ethanol concentrations are presented in Figure 1, plate (b). In spite of the current increase, the general features observed during the positivegoing sweep are very similar in the four exemplified cases. A remarkable difference, though less important from the electrocatalytic point of view, is observed along the negativegoing scan, namely the smaller contribution of gold oxide reduction accompanying the increase in the ethanol concentration. Such behaviour can be simply rationalized in terms of the increase in the availability of ethanol molecules to interact with gold oxides during its initial stages of electrochemical reduction.

Chronoamperometric curves, obtained after applying a potential step from 50 to $600 \mathrm{mV}$ vs. RHE, and different ethanol concentrations are shown in Figure 2 (a). The values of the current density at 300 and at 600 seconds are given as 
a function of ethanol concentration in Figure 2 (b). Although the values of polarization time of $300 \mathrm{~s}$ do not seem strictly stationary, specially for high ethanol concentrations, this relatively short time was chosen in order to allow the comparison with the FTIR data presented below. Nevertheless, a similar trend is observed for $t=600 \mathrm{~s}$. The experiments were done, at least, in triplicate and the imprecision is incorporated as error bars in the values shown in Figure 2 (b).

The shape of the chronoamperometric curves is similar to that generally observed for the electrooxidaton of $\mathrm{C} 1$ and $\mathrm{C} 2$ molecules at low overpotentials, and the strong decay shortly after the potential step is attributed to the formation of inactive adsorbed intermediates that act as poison. The data for the catalyst activity after 300 and $600 \mathrm{~s}$ as a function of the ethanol concentration shows a continuous growth up to about $2 \mathrm{M}$ and then a decrease for $[\mathrm{EtOH}]=3 \mathrm{M}$. It is important to notice that the quasi-stationary data obtained in the

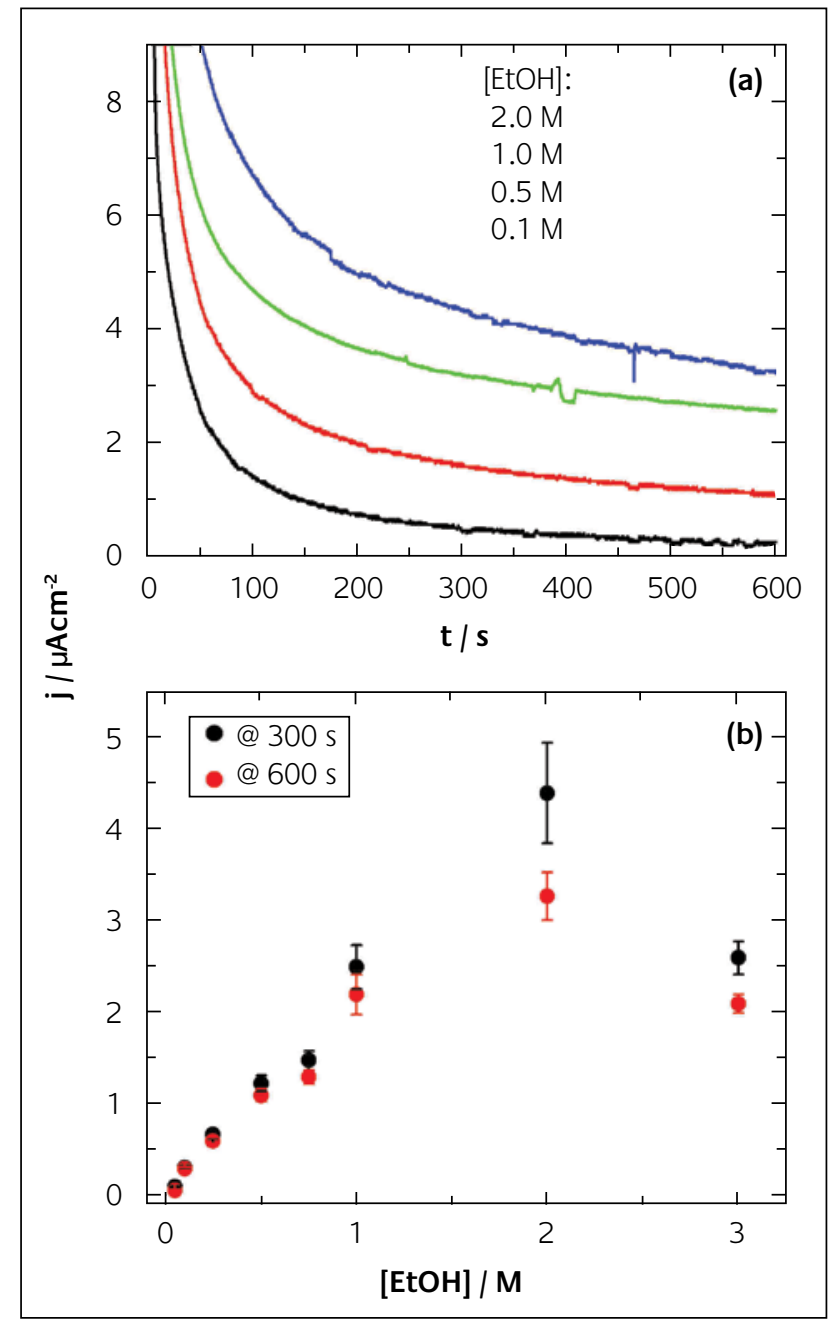

Figure 2

(a) Chronoamperometric curves for polycrystalline Au after application of a potential step from 50 to $600 \mathrm{mV}$ vs. RHE obtained at different ethanol concentrations. (b) Current density for ethanol electrooxidation taken from the curves in (a), after 300 seconds of polarization, plotted as a function of the concentration of ethanol. The disk shaped gold electrode was used in these experiments and the meniscus configuration adopted chronoamperometric experiments at $600 \mathrm{mV}$ vs. RHE are different than those observed under voltammetric conditions (see below).

The data obtained for high ethanol concentration, specially after $600 \mathrm{~s}$, does not allow to unambiguously differentiating the general trend between a maximum at about $2 \mathrm{M}$ or a plateau between 1 and $3 \mathrm{M}$. In any case, the behaviour is very different of that observed during ethanol electrooxidation on platinum and in acid media. In a recent work, Camara and Iwasita [46] studied the impact of ethanol concentration on its electrooxidation over a smooth platinum electrode in acid medium. As in the present case, the authors used in situ FTIR spectroscopy coupled to electrochemical techniques. The authors observed that a current maximum of $8 \mathrm{\mu Acm}^{-2}$ for [EtOH] of about 0.5 M. Moreover the volcano type of current density $x[\mathrm{EtOH}]$ curve was captured in the overall charge based on the yields of soluble products (viz. $\mathrm{CO}_{2}$, acetaldehyde, and acetic acid). The difference between the ethanol

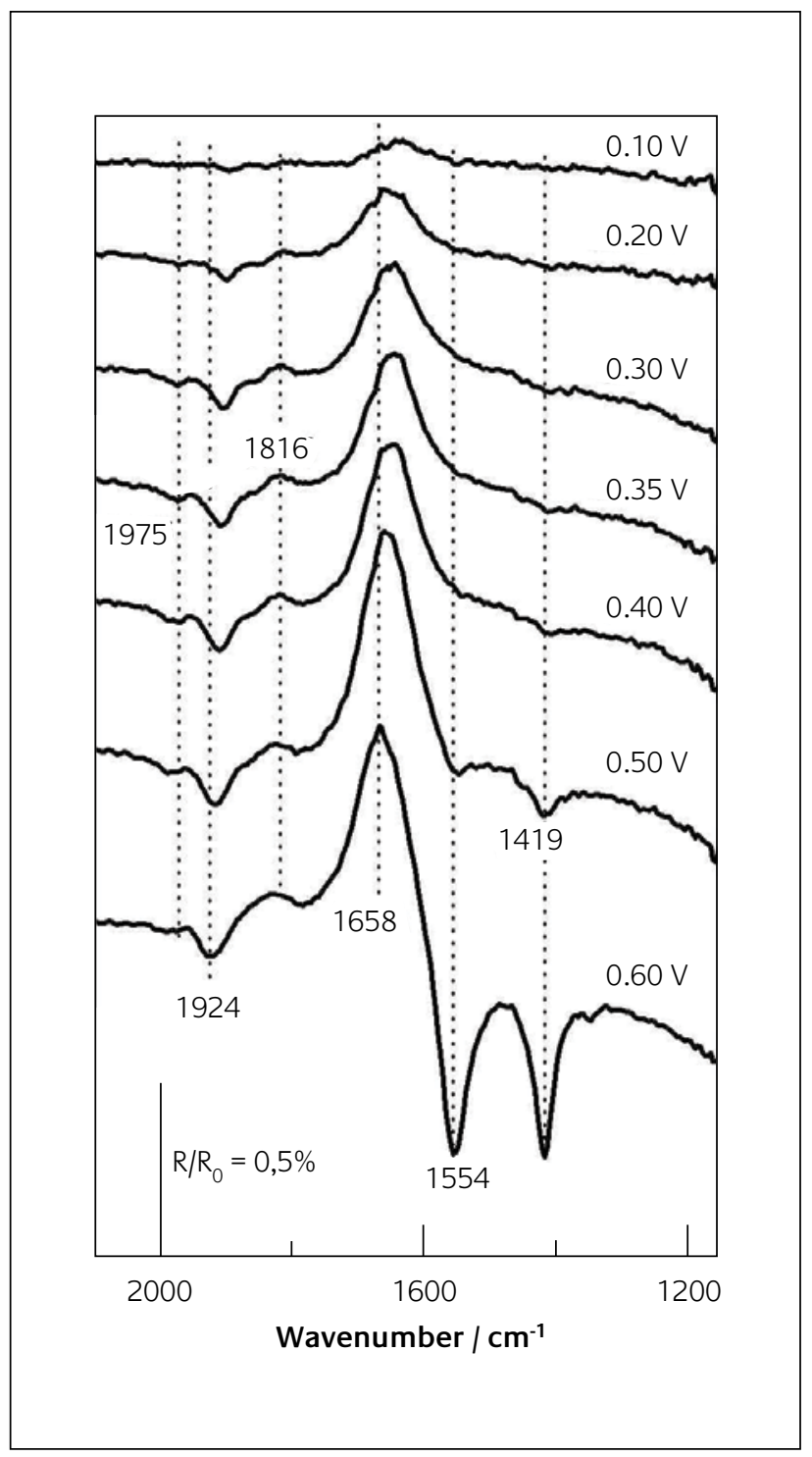

Figure 3

FTIR absorption-reflection spectra of polycrystalline Au in 0.1M $\mathrm{CH}_{3} \mathrm{CH}_{2} \mathrm{OH}+0.1 \mathrm{KOH}$ aqueous solution. Reference spectrum obtained at $0.05 \mathrm{~V}$ vs. RHE; resolution: $8 \mathrm{~cm}^{-1} ; 100$ scans 
concentration at which the maximum conversion is observed at 'platinum in acid' and in 'gold in alkali' systems can be rationalized in terms of the competition for surface sites between ethanol molecules and hydroxyl species. In acid media, due to the negligible $\mathrm{OH}^{-}$(and usually small supporting electrolyte anion) concentration, a small ethanol concentration suffices to reach the maximum reaction rate. In contrast, given the high concentration of hydroxyl species in alkali, only at very high ethanol concentrations the highest conversion is observed. Moreover, this scenario is further supported by the fact that adsorption is in general weaker on gold than on platinum surfaces.

The effect of ethanol concentration was studied by in situ FTIR spectroscopy at different applied potentials. Since we focused our attention on the early stages of ethanol electrooxidation, the experiments were performed at potentials up to $600 \mathrm{mV}$ vs. RHE. Spectra obtained for $0.5 \mathrm{M}$ $\mathrm{C}_{2} \mathrm{H}_{6} \mathrm{O}$ in $0.1 \mathrm{M} \mathrm{KOH}$ aqueous solution are given in Figure 3 at different potentials. First, a reference spectrum $R_{0}$ was

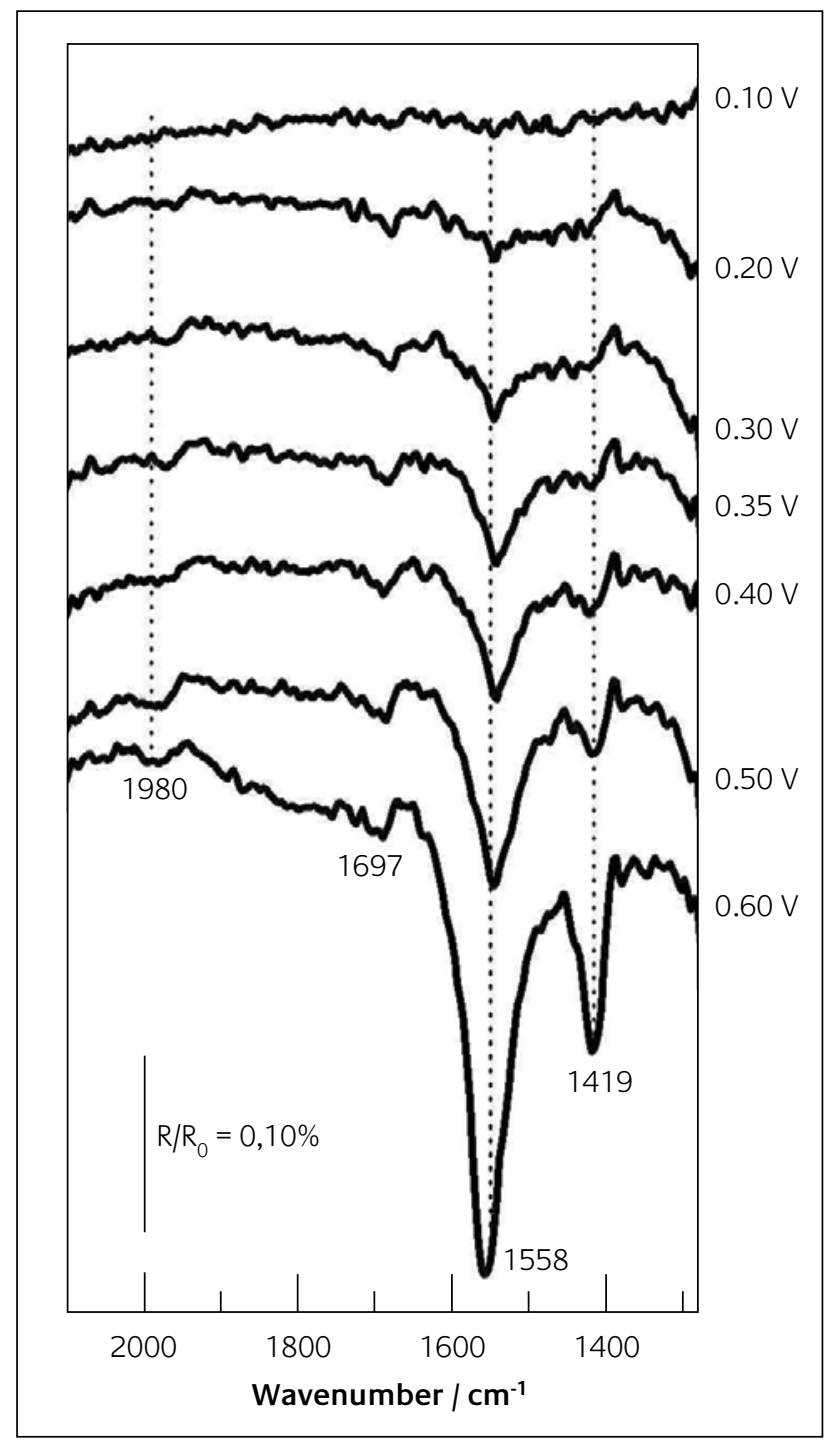

Figure 4

FTIR absorption-reflection spectra of polycrystalline Au in $0.05 \mathrm{M}$ $\mathrm{CH}_{3} \mathrm{CH}_{2} \mathrm{OH}+0.1 \mathrm{M} \mathrm{KOH}$ solution, using $\mathrm{D}_{2} \mathrm{O}$ as solvent. Reference spectrum obtained at $0.05 \mathrm{~V}$; resolution: $8 \mathrm{~cm}^{-1} ; 100$ scans measured at $50 \mathrm{mV}$ vs. RHE and then sample spectra were collected after applying successive potential steps of $50 \mathrm{mV}$ up to $600 \mathrm{mV}$ vs. RHE. The small bands in the range of 2000$1800 \mathrm{~cm}^{-1}$ are attributed to adsorbed carbon monoxide, $\mathrm{CO}_{\mathrm{ad}}$. This attribution is supported by addition experiments in the presence of dissolved $\mathrm{CO}$ in alkali (not shown). In those experiments, CO was adsorbed on the gold surface at $50 \mathrm{mV}$ vs. RHE for $15 \mathrm{~s}$. After that, the solution was purged with nitrogen and the potential increased stepwise up to $600 \mathrm{mV}$ vs. RHE and the spectra registered. Bands at 1986 and 1919 $\mathrm{cm}^{-1}$ start growing at about $100 \mathrm{mV}$ vs. RHE and, following Markovic and co-workers [29], were identified as bridge and multi-coordinated adsorbed CO, respectively. Moreover, concomitantly to the transition in the $\mathrm{CO}_{\text {ad }}$ population from multi to bridge coordinated, the $\mathrm{CO}_{\text {ad }}$ electrooxidation is also seen as a band at $1400 \mathrm{~cm}^{-1}$ relative to carbonate, which start increasing at about $400 \mathrm{mV}$. The presence of $\mathrm{CO}_{\mathrm{ad}}$ at potentials as small as $200 \mathrm{mV}$ vs. RHE indicates that some ethanol molecules are totally dissociated on gold surface, in contrast to earlier beliefs [32].

The strong band going up at $1640 \mathrm{~cm}^{-1}$ corresponds to the $\mathrm{OH}$ deformation of water molecules not compensated in the thin layer. The other two bands at $1554 \mathrm{~cm}^{-1}$ and $1418 \mathrm{~cm}^{-1}$ correspond respectively to the asymmetric and symmetric stretching modes of $\mathrm{CO}_{2}^{-}$group of the acetate ions [47]. Unfortunately, the band at $1400 \mathrm{~cm}^{-1}$ associated to carbonate ions, eventually formed from $\mathrm{CO}_{2}$ [31], could not be monitored because of the interference of the asymmetric stretching $\left(1418 \mathrm{~cm}^{-1}\right)$ of the acetate $\mathrm{CO}_{2}{ }^{-}$group.

To circumvent the difficulty due to the presence of water bands in the region between $1700 \mathrm{~cm}^{-1}$ and $1400 \mathrm{~cm}^{-1}$, we have carried out similar experiments as in Figure 3 but using deuterium oxide $\left(D_{2} O\right)$ as solvent. Results are depicted in Figure 4 . Without the interference of the $\mathrm{OH}$ bending mode of water molecules, it is possible to observe that the band assigned to acetate $\left(1556 \mathrm{~cm}^{-1}\right)$ starts being discerned already at $200 \mathrm{mV}$ vs. RHE and grows for increasing positive potentials. The other band near $1419 \mathrm{~cm}^{-1}$ starts developing at potentials around $400 \mathrm{mV}$ vs. RHE.

Figure 5 depicts some selected spectra obtained for different ethanol concentration collected after $300 \mathrm{~s}$ of polarization at $600 \mathrm{mV}$ vs. RHE. The relatively short time was used to avoid the diffusion of produced species out of the thin layer. At a first glance, only bands attributed at acetate ions (1562 cm-1 and $1416 \mathrm{~cm}^{-1}$ ) have a linear increase with ethanol concentration. At high ethanol concentrations, a small band at $1704 \mathrm{~cm}^{-1}$ attributed to the carbonyl group stretching is also observed and could be associated, in principle, to traces of dissolved acetaldehyde.

The production of acetate ions during ethanol electrooxidation on gold surfaces in alkaline media have been previously suggested on the basis of Tafel plots [48-52] and chromatographic analysis [32]. However, the results provided in the present contribution seem to be the first unambiguous spectroscopic evidence of the presence of acetate ions. The acetaldehyde formation requires only the de-protonation of 


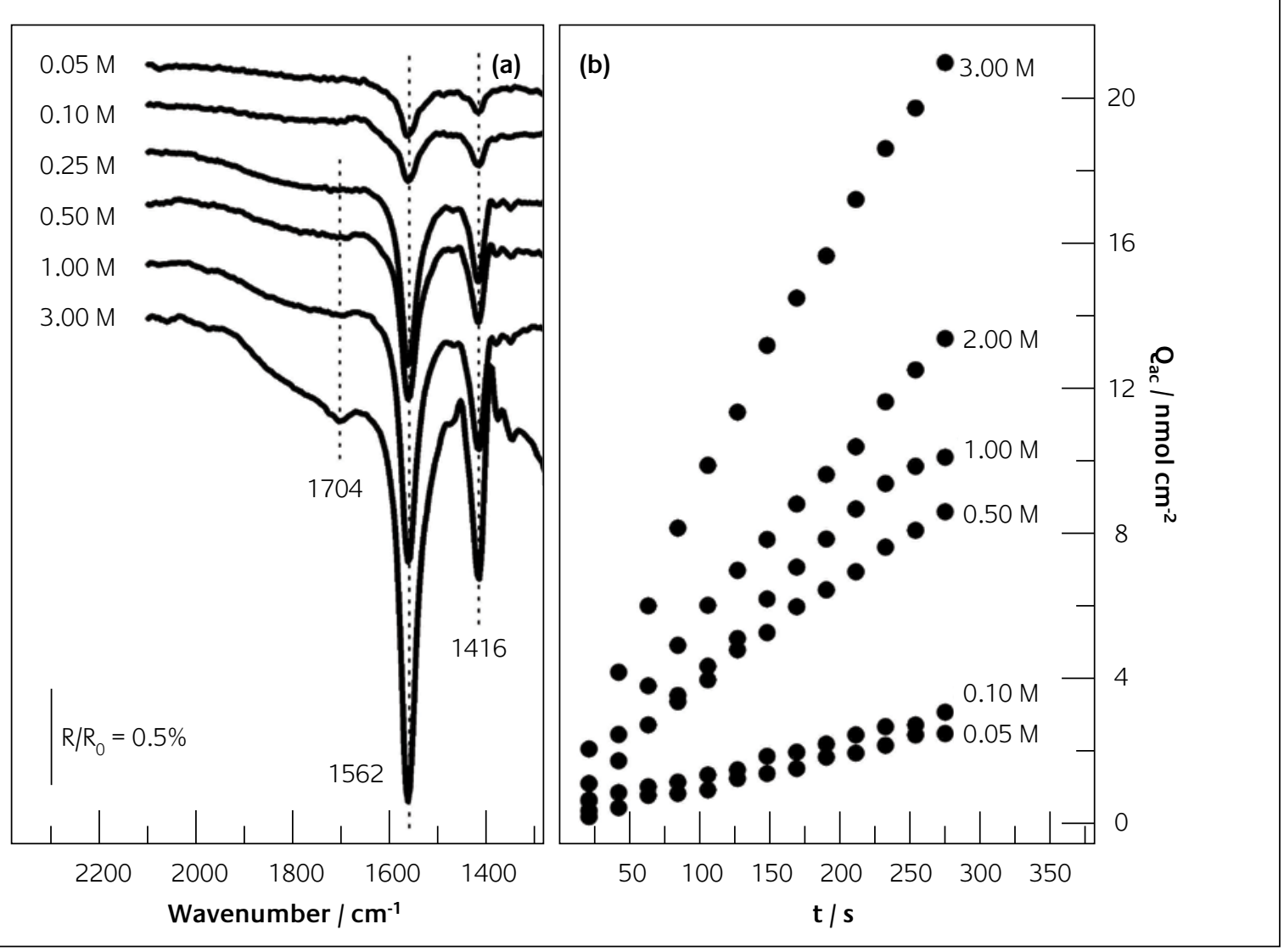

\section{Figure 5}

(a) In situ FTIR spectra taken after 5 min of polarization at $600 \mathrm{mV}$ vs. RHE at different ethanol concentrations. (b) Quantity of acetate ions, $Q_{a c}$, formed as a function of time at $E=600 \mathrm{mV}$ vs. RHE and at different ethanol concentrations. Base electrolyte $0.1 \mathrm{M} \mathrm{KOH}$ in $\mathrm{D}_{2} \mathrm{O}$

ethanol molecule, nevertheless, we were not able to detect the acetaldehyde band in solution (asymmetric stretching at $933 \mathrm{~cm}^{-1}$ ) [53]. This can be due to an intrinsic difficulty in detecting acetaldehyde, thanks to its low capability to adsorb. In addition, considering the rapid growth of the amount of acetate ions as a function of time (Figure 5(a)), it could be the

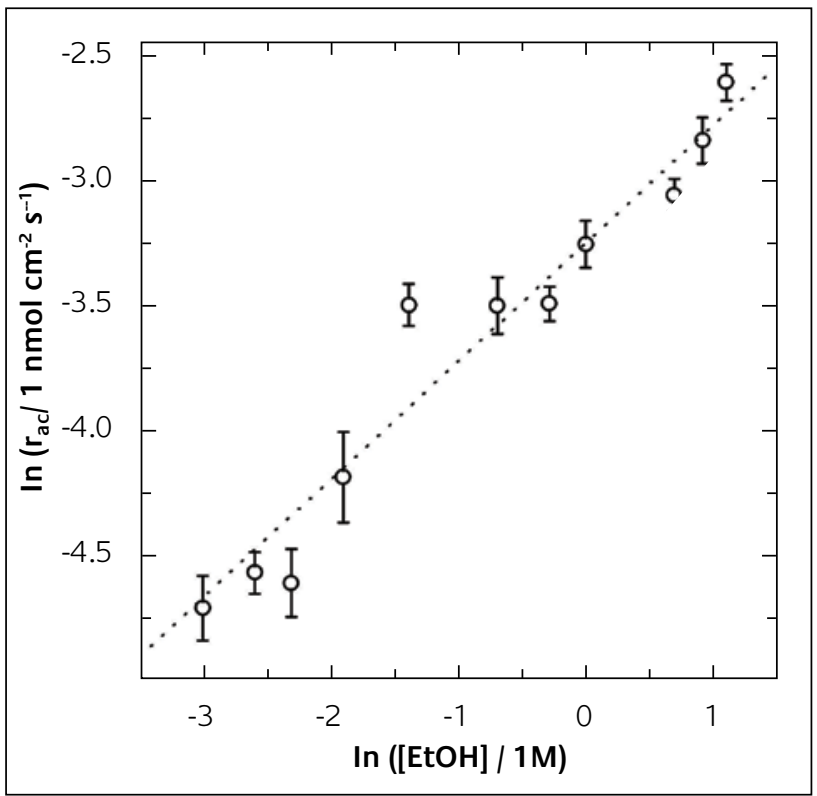

Figure 6

Plots of In ( $r_{a d}$ versus In ([EtOH]). See text for details case that the absence of acetaldehyde under these conditions may be caused by its fast conversion into acetate ions, similarly to that observed in acid medium and on platinum electrocatalyst [46]. Using the value of the effective absorption coefficient corresponding to the asymmetric stretching at $1550 \mathrm{~cm}^{-1}\left(\varepsilon_{\text {eff }}=1.7 \times 10^{4} \mathrm{M}^{-1} \mathrm{~cm}^{-1}\right)$ of acetate ions provided by Weaver and co-workers [31], one can calculate the amount $\mathrm{Q}_{\mathrm{ac}}\left(\mathrm{mol} \mathrm{cm} \mathrm{cm}^{-2}\right)$ of acetate ions inside the thin layer with $\mathrm{Q}_{\mathrm{ac}}=$ $\mathrm{A}_{\mathrm{i}} / \varepsilon_{\text {eff }}$. The behaviour of $\mathrm{Q}_{\mathrm{ac}}$ is depicted in Figure 5(b) as a function of the ethanol concentration. A fairly linear behaviour was found for all ethanol concentrations studied and for times up to $280 \mathrm{~s}$, indicating that acetate ions are produced at a nearly constant rate for each ethanol concentration.

The reaction rate of acetate ions, $r_{a c}$, produced during ethanol electrooxidation can be estimated at constant potential ( $E=600 \mathrm{mV}$ vs. RHE), ethanol concentration and temperature, by equation 1 ,

$r_{\mathrm{ac}}=\left(\frac{\partial \mathrm{Q}_{\mathrm{ac}}}{\partial \mathrm{t}}\right)_{\mathrm{E},[\mathrm{EtOH}], \mathrm{T}}$

Plots of $r_{\text {ac }}$ versus [EtOH] are given in Figure 6 in a In-In scale. The error in the $r_{\text {ac }}$ estimation was inferior to $4.5 \%$ and it is indicated in the error bars. In contrast to the limit observed in the overall reaction rate for high ethanol concentrations, c.f. Figure 2(b), the reaction of acetate ions produced shows a continuous growth with [EtOH]. 
The dependence of $r_{a c}$ with the ethanol concentration can be expressed in terms of the rate equation,

$$
\mathrm{r}_{\mathrm{ac}}=\mathrm{k}^{\prime}[\mathrm{EtOH}]^{\mathrm{n}}
$$

in which $n$ accounts for the reaction order of acetate production with respect to ethanol concentration, and $k^{1}$ is the rate constant.

As indicated in equation (2), the reaction order $n$, is obtained by,

$$
\mathrm{n}=\left(\frac{\partial \ln \mathrm{r}_{\mathrm{ac}}}{\partial \ln [\mathrm{EtOH}]}\right)_{\mathrm{E}, \mathrm{T}} \text {. }
$$

Linear fitting of the data presented in Figure 6, results in a reaction order for the acetate production with respect to ethanol of about 0.5 (actually $0.47 \pm 0.02$ ).

Based on long term chromatographic analysis, TremiliosiFilho et al. [32] proposed a general mechanism of the ethanol electrooxidation on polycrystalline gold electrodes in alkaline media. The authors found the experimental number of transferred electrons of 4.25 and identified acetic acid (actually, acetate ions in alkaline media) as the main product. The electrolysis was carried out at considerable high applied potential (1200 and $1600 \mathrm{mV}$ vs. RHE) and for about 5 hours. Under those conditions, the authors proposed a general mechanism in which a Langmuir-Hinshelwood(LH) step in which adsorbed ethoxi reacts with adsorbed oxygenated species $\left(\mathrm{OH}_{\mathrm{ad}}\right)$. For a $\mathrm{LH}$ mechanism, the reaction rate starts decreasing when the concentration of one of the adsorbing species increases beyond a certain threshold [54]. Results obtained in the present investigation, namely the continuous increase of the production rate of acetate ions even for very

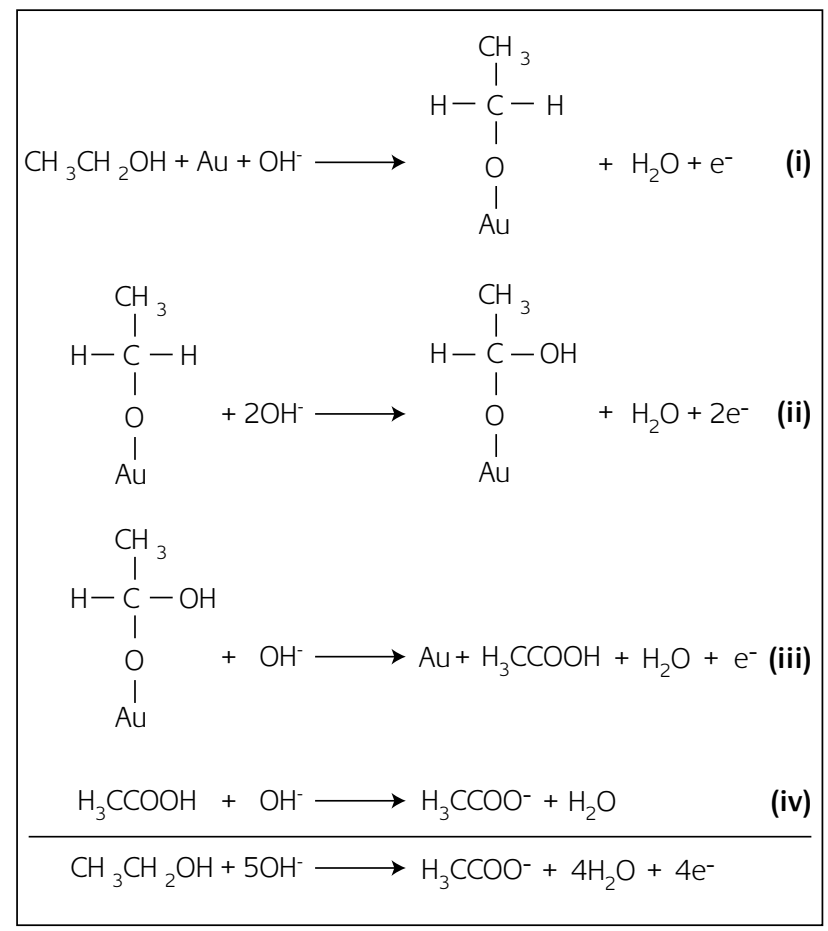

Scheme 1 high ethanol concentrations, seem to contradict this scenario. Scheme 1 shows a tentative mechanism based on that proposed by Tremiliosi-Filho et al. [32]. In this scheme, the initial adsorption step occurs via an ethoxi intermediate (i). However, differently from the original formulation [32], step (ii) comprises the interaction of adsorbed ethoxi and nonadsorbed $\mathrm{OH}^{-}$species, via the so-called Eley-Rideal(ER) mechanism [55-57]. In this case, the activated complex would be formed between adsorbed species and other nonadsorbed species close to the electrode surface. For this mechanism, as a result of the increase of concentration of one of the two reacting species (i.e. either the adsorbed or the non-adsorbed one) there is an increase of the reaction rate up to a certain limiting value, but no decrease is expected at higher concentrations. It should be emphasized that the LH step proposed by Tremiliosi-Filho et al. [32] can indeed be the operating one at high potentials where the gold surface is considerably covered by oxygenated species, which is unlikely to be the case at $600 \mathrm{mV}$ vs. RHE as in the present study.

In a series of papers, Betowska-Brzezinska et al. [48-52] discussed the electrooxidation of mono- and polyhydric alcohols on gold and platinum surfaces. For primary alcohols in alkaline media, the authors identified the cleavage of the $\mathrm{C}-\mathrm{H}$ bond on the $\alpha$-carbon during the initial adsorption stage as the rate determining step. Moreover, they speculated that a (symmetric) surface transition state would be formed by the interaction between the alcohol molecule and hydroxyl ions at the interface. In this scheme, further alcohol electrooxidation steps would proceed very fast and have no influence on the overall rate. Important to the present discussion is the fact that the adsorbed alcohol residue interacts with solution hydroxyl ions, corroborating, therefore, with our experiments. Furthermore, in their scheme, the adsorption step occurs via the alcohol derivative residue $\mathrm{Au}-\mathrm{CHOH}-\mathrm{CH}_{3}$, instead of the ethoxi intermediate as in Scheme 1. Based on in situ spectroscopy, both alcohol and ethoxi adsorbed residues have been either directly observed (alcohol residue) or indirectly deduced (ethoxi adsorbate), during ethanol electrooxidation on platinum electrode in acidic media $[58,59]$. Contrariwise, neither in Betwoska-Brzezinska et al. [48-52] nor in TremiliosiFilho et al. [32] results, the very nature of the initial adsorbate has been directly identified. Furthermore, unlike the usual situation at the solid/gas interface $[55,56]$, it seems there is no unquestionable evidence of the presence of adsorbed ethoxi intermediate under electrochemical environment. Data of atom surface energy points to the higher stability of the Au-O bond in comparison to the $\mathrm{Au}-\mathrm{C}$ one, in contrast to that of platinum, where the Pt-C bond is more stable [57]. Of course, thermodynamical arguments can be used just as a guide, when more appropriate experimental data is not available. In the context of the present discussion, the key point to be stressed in Scheme 1 is the suggestion of the occurrence of an ER type of route in step (ii), and the specific identity of the initial adsorbed species can be still considered an open question. 
Borkowska et al. [60] investigated the electrooxidation of methanol on both polycrystalline and single crystal gold surfaces. Besides the superior reaction rates in alkaline medium, when compared to acid and neutral media, the authors reported studies on the methanol and potassium hydroxide concentrations. For $[\mathrm{KOH}]=0.1 \mathrm{M}$, a continuous growth in the reaction current with the methanol concentration was observed up to about $6 \mathrm{M}$. Experiments using $[\mathrm{KOH}]=0.01 \mathrm{M}$, however, reveals a slight decrease in the reaction current for very high methanol concentrations ([MetOH] > 4.5 M), which, in principle, would be a signature of the LH mechanism for the overall reaction. However, those results cannot be taken as contradictory to our interpretation. In addition to the fact that the systems are not completely equivalent, i.e. Borkowska et al. [60] studied methanol whereas we report on the ethanol electrooxidation, their discussion about the effect of the alcohol concentration on the reaction rate was carried out in terms of the voltammetric peak current, which of course can carry different contributions. Indeed, the use of non-stationary rates to infer about reaction kinetics and mechanism is, in many cases, not justified. The peak current values used were taken at considerable high potentials, in contrast to the analysis presented here at $\mathrm{E}=$ $600 \mathrm{mV}$ vs. RHE. Finally, results of Borkowska et al. [60] and those given in Figure 2(b) report to a global electrooxidation process, instead, the ER mechanism discussed in Scheme 1 accounts for the step concerned with the production of acetate intermediate.

\section{Concluding remarks}

The present work reports the study of the ethanol electrooxidation on polycrystalline gold electrode in alkaline medium. The investigation was carried out by means of chronoamperometry, cyclic voltammetry and in situ FTIR spectroscopy. The studies were focused on the early stages of ethanol electrooxidation, namely at fairly low potentials ( $E=$ $600 \mathrm{mV}$ vs. RHE) and for relatively short times ( $\mathrm{t}<300 \mathrm{~s}$ ). The main conclusions are summarized as follows:

a Chronoamperometric experiments at $\mathrm{E}=600 \mathrm{mV}$ vs. RHE show a current increase accompanying the increase in the ethanol concentration up to about $2 \mathrm{M}$, where a slight current decrease is observed for $[\mathrm{EtOH}]=3 \mathrm{M}$;

b The presence of bands in the region between 1980 and $1816 \mathrm{~cm}^{-1}$ starting at about $200 \mathrm{mV}$ vs. RHE was attributed to adsorbed CO and indicates that the cleavage of the C-C bond might occur at very low overpotentials during ethanol adsorption on gold surface;

c Acetate ions were identified as the main product of ethanol electrooxation. The amount of dissolved acetate ions was monitored via the band at $1558 \mathrm{~cm}^{-1}$ and followed as a function of time. It was found to increase linearly with time up to 300s. Moreover, the rate of acetate formation increased linearly with ethanol concentration irrespective to the current maxima reached at high ethanol concentration mentioned in (a). The reaction order of acetate formation with respect to ethanol concentration was estimated as 0.5 . Finally, it was suggested that acetate ions were formed via an Eley-Ridel mechanism between adsorbed ethoxi and non-adsorbed oxygenated species;

d Given the interference of the asymmetric stretching $\left(1418 \mathrm{~cm}^{-1}\right)$ of the acetate $\mathrm{CO}_{2}^{-}$group, were not able to follow the eventual production of free carbonate ions (at $1403 \mathrm{~cm}^{-1}$ ).

\section{Acknowledgements}

The authors would like to acknowledge Prof. Dr. G. TremiliosiFilho and Prof. Dr. G. A. Camara for fruitful discussions and to the Brazilian agencies FAPESP (Process \# 04/04528-0) and CNPq (Process \# 154379/2006-9) for financial support.

\section{About the authors}

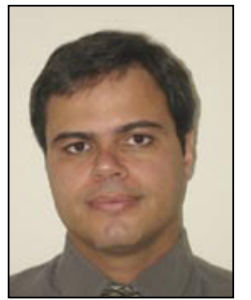

Roberto Batista de Lima, graduated in Chemistry at the UFRN (2001), did his Master (2003) and PhD in Physical Chemistry at the IQSC - Universidade de Sao Paulo (2006), under the supervision of Prof. Dr. Teresa Iwasita. Then he was awarded a post-doc position in Prof. Varela's Group at the same institution. His scientific interests are electrocatalysis and spectroelectrochemical techniques.

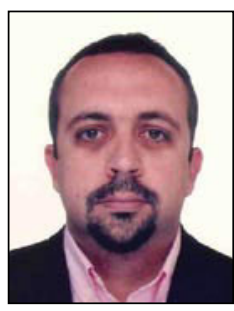

Hamilton Varela graduated in Chemical Engineering at the UFRN (1998), did his Master in Physical Chemistry at the IQSC - Universidade de Sao Paulo (2002), his $\mathrm{PhD}$ in Chemistry at the Fritz-HaberInstitut of the Max Planck Society under the supervision of Prof. Dr. Katharina Krischer (2004), and a post-doc at the Physics Department Technical University Munich. Since 2007 he is an assistant Professor at the IQSC - USP. His current interests are electrocatalysis and nonlinear dynamics of fuel cell relevant reactions and self-organization in reaction-transport systems.

\section{References}

1 R. Holze, J. Electroanal. Chem, 1988, 246, 449

2 L. W. H. Leung, M. J. Weaver, J. Phys. Chem, 1988, 92, 4019

3 T. Iwasita, J. Braz. Chem. Soc, 2002, 13, 401

4 J. P. I. de Souza, S. L. Queiroz, K. Bergamaski, E. R. Gonzalez, F. C. Nart, J. Phys. Chem. B, 2002, 106, 9825

5 C. Lamy, A. Lima, V. Lerhun, F. Delime, C. Coutanceau, J. M. Leger, J. Power Sources, 2002, 105, 283

6 H. Wang. Z. Jusys, R. J. Behm, J. Phys. Chem. B, 2004, 108, 19413 
7 F. Vigier, C. Coutanceau, A. Perrard, E. M. Belgsir, C. Lamy, J. App. Electrochem, 2004, 34, 439

8 G. A. Camara, R. B. Lima, T. Iwasita, J. Electroanal. Chem, 2005, 585, 128

9 M. H. Shao, R.R. Adzic, Electrochim. Acta, 2005, 50, 2415

10 F. Vigier, S. Rousseau, C. Coutanceau, J. M. Leger, C. Lamy, Topics in Catalysis, 2006, 40, 111

11 J. F. Gomes, B. Busson, A. Tadjeddine, J. Phys. Chem. B, 2006, 110, 5508

12 H. Wang, Z. Jusys, R. J. Behm, J. Power Sources, 2006, 154, 351

13 L. Colmenares, H. Wang, Z. Jusys, L. Jiang, S. Yan, G. Q. Sun, R. J. Behm, Electrochim. Acta, 2006, 52, 221

14 T. Lopes, E. Antolini, F. Colmati, E. R. Gonzalez, J. Power Sources, 2007, 164, 111

15 F. Colmati, E. Antolini, E. R. Gonalez, J. Electrochem. Soc, 2007, 154, B39

16 R. Chetty, K. Scott, Electrochim. Acta, 2007, 52, 4073

17 G. A. Camara, R. B. de Lima, T. Iwasita, Electrochem. Comm, 2004, 6, 812

18 W. J. Zhou, W. Z. Li, S. Q. Song, Z. H. Zhou, L. H. Jiang, G. Q. Sun, Q. Xin, K. Poulianitis, S. Kontou, P. Tsiakaras, J. Power Sources, 2004, 131, 217

19 V. P. Santos, V. Del Colle, R. B. de Lima, G. Tremiliosi-Filho, Langmuir, 2004, 20, 11064

20 J. Mann, N. Yao, A. B. Bocarsly, Langmuir, 2006, 22, 10432

21 F. Vigier, C. Coutanceau, F. Hahn, E. M. Belgsir, C. Lamy, J. Electroanal. Chem, 2004, 563, 81

22 D. M. dos Anjos, K. B. Kokoh, J. M. Leger, A. R. de Andrade, P. Olivi, G. Tremiliosi-Filho, J. App. Electrochem, 2006, 36, 1391

23 L. D. Burke, P. F. Nugent, Gold Bulletin, 1998, 31, 39

24 G. L. Beltramo, T. E. Shubina, M. T. M. Koper, ChemPhysChem, 2005, 6, 2597

25 A. S. Lin, J. Lin, J. C. Huang, Gold Bulletin, 2007, 40, 82

26 H. Kita, H. Nakajima, K. Hayashi, J. Electroanal. Chem, 1985, 190, 141

27 G. J. Edens, A. Hamelin, M. J. Weaver, J. Phys. Chem, 1996, 100, 2322

28 B. Blizanac, C. A. Lucas, M. E. Gallagher, M. Arenz, P. N. Ross, N. M. Markovic, J. Phys. Chem. B, 2004, 108, 625

29 B. Blizanac, M. Arenz, P. N. Ross, N. M. Markovic, J. Am. Chem. Soc, 2004, 126, 10130

30 B. Beden, I. Cetin, A. Kahyaoglu, U. Takky, C. Lamy, J. Catal. 104 (1987) 37-46

31 S. C. Chang, Y. Ho, J. M. Weaver, J. Am. Chem. Soc, 1991, 113, 9506

32 G. Tremiliosi-Filho, E. R. Gonzalez, A. J. Motheo, E. M. Belgsir, J. M. Leger, C. Lamy, J. Electroanal. Chem, 1998, 444, 31

33 K. Yahikozawa, K. Nishimura, M. Kumazawa, N. Tateishi, Y. Takasu, K. Yasusa, Y. Matsuda, Electrochem. Acta, 1992, 37, 453

34 J. Hernández, J. Solla-Gullón, E. Herrero, A. Aldaz, J. M. Feliu, Electrochem.
Acta, 2006, 52, 1662

35 B. Xing and O. Savadogo. Electrochem. Comm, 2000, 2, 697

36 T. N. Danks, R. C. T. Slade and J. R. Varcoe. J. Mater. Chem, 2002, 12, 3371

37 J. R. Varcoe, R. C. T. Slade, Fuel Cells, 2005, 5, 187

38 R. Ferrigno, A. D. Stroock, T. D. Clark, M. Mayer and G. M. Whitesides, J. Am. Chem. Soc, 2002, 124, 12930

39 E. R. Choban, L. J. Markoski, A. Wieckowski and P. J. A. Kenis, J. Power Sources, 2004, 128, 54

40 J. S. Spendelow, G. Q. Lu, P. J. A. Kenis, A. Wieckowski, J. Electroanal. Chem, 2004, 568, 215

41 G. Tremiliosi-Filho, L. H. Dall'Antonia, G. Jerkiewicz, J. Electroanal. Chem, 2005, 578, 1

42 T. Iwasita, F. Nart, W. Vielstich, C. Ber. Bunsenges. Phys. Chem, 1990, 94, 1030

43 T. Iwasita, F. C. Nart. In: Gerischer, H.; Tobias, Ch., (Eds.) Advances in Electrochemical Science and Engineering, VCH: Weinheim, 1995, 4, 123

44 H. Angerstein-Kozlowska, B. E. Conway, B. Barnett, J. Mozota, J. Electroanal. Chem, 1979, 100, 417

45 L. D. Burke, L. M. Hurley, J. Solid State Electrochem, 2002, 6, 101

46 G. A. Camara, T. Iwasita, J. Electroanal. Chem, 2005, 578, 315

47 G. Socrates, Infrared Characteristic Group Frequencies, John Wiley \& Sons: Chichester, 2001

48 M. Betowska-Brzezinska, W. Vielstich, Electrochim. Acta, 1977, 22, 1313

49 M. Betowska-Brzezinska, Electrochim. Acta, 1979, 24, 409

50 M. Betowska-Brzezinska, Electrochim. Acta, 1980, 25, 267

51 R. Holze, M. Betowska-Brzezinska, Electrochim. Acta, 1985, 30, 937

52 M. Betowska-Brzezinska, T. Uczak, R. Holze, J. App. Electrochem, 1997, 27, 999

53 P. Gao, S. C. Chang, Z. Zhou, M. J. Weaver, J. Electroanal. Chem, 1989, 272, 161

54 K. J. Laidler Chemical kinetics,. Harper \& Row Publishers, New York, 1987, 3rd edn

55 G. A. Somorjai, Introduction to Surface Chemistry and Catalysis, John Wiley and Sons, New York, 1994, 1st edition

56 R. I. Masel, Principles of adsorption and reaction on solid surfaces, John Wiley and Sons, New York, 1996, 1st edition

57 R. I. Masel, Chemical kinetics, John Wiley and Sons, New York, 2001, 1st edition

58 T. Iwasita, E. Pastor, Electroch. Acta, 1994, 39, 531

59 J. F. Gomes, Private communication, 2007

60 Z. Borkowska, A. T. Zielinska, G. Shul, Electrochim. Acta, 2004, 49, 1209 